\title{
Prostaglandin synthesis by Day-6 rabbit blastocysts in vitro
}

\author{
M. J. K. Harper, M. A. Jones*, C. J. Norris and D. S. Woodard \\ Department of Obstetrics and Gynecology, University of Texas Health Science Center, \\ San Antonio, Texas 78284, USA
}

\begin{abstract}
Summary. Day-6 rabbit blastocysts were recovered from superovulated donor animals, washed in ice-cold Krebs-Ringer-bicarbonate (KRB) buffer, pooled and randomly allocated to polypropylene incubation tubes, usually 10 blastocysts in $1 \mathrm{ml} \mathrm{KRB}$. The blastocysts were ruptured with a dissecting needle and incubated at $37^{\circ} \mathrm{C}$ for periods of 1-3 h with $10 \mu \mathrm{Ci}\left[{ }^{3} \mathrm{H}\right.$ ]arachidonic acid/tube. A control tube without blastocysts was run in each experiment. At the end of the incubation, the samples were acidified, extracted with ethyl acetate, dried down and resuspended in h.p.l.c. column solvent. The radioactivity from the control tube eluting from the h.p.l.c., using a solvent system for prostaglandins (PGs), was subtracted from each experimental run in the same experiment. The remaining radioactivity constituted $0 \cdot 14 \%$ of the original $\left[{ }^{3} \mathrm{H}\right]$ arachidonic acid added to each incubation tube. This was considered to have been the result of conversion of the radiolabelled arachidonic acid to prostanoids. In the absence of $10 \mathrm{~mm}$-EDTA no conversion occurred, whereas in its presence peaks of radioactivity co-eluting with $\left[{ }^{3} \mathrm{H}\right] \mathrm{PGF}-2 \alpha$ and $\left[{ }^{3} \mathrm{H}\right] \mathrm{PGE}-2$ were seen. A third peak that eluted was either 15-keto metabolites of these PGs or PGD-2. These 3 peaks were always significantly above background, and usually did not differ from each other. No differences in amount of conversion could be related to incubation time. Addition of indomethacin $(100 \mu \mathrm{g} / \mathrm{ml})$ or radioinert arachidonic acid $(10 \mu \mathrm{g} / \mathrm{ml})$ inhibited production of $\left[{ }^{3} \mathrm{H}\right] \mathrm{PG}$, even in the presence of EDTA. Removal of calcium from the incubation medium was per se without effect. Addition of atropine $(0.15 \mathrm{~mm})$ or carbachol $(0.15 \mathrm{~mm})$ in the presence or absence of EDTA did not change the pattern of conversion of $\left[{ }^{3} \mathrm{H}\right]$ arachidonic acid to [ $\left.{ }^{3} \mathrm{H}\right] \mathrm{PG}$. These experiments demonstrate that rabbit blastocysts have the capacity for de-novo synthesis of PGs from exogenous substrate, when utilization of endogenous substrate is inhibited. The extent of conversion observed may not be a true reflection of the capacity for conversion of endogenous substrate.
\end{abstract}

Keywords: rabbit; blastocysts; prostaglandins

\section{Introduction}

The presence of prostaglandins (PGs) in Day-6 rabbit blastocysts was first described by Dickmann \& Spilman (1975). Since that time many investigators have confirmed this observation and enlarged the original findings to include blastocysts of different ages (Dey et al., 1980; Sharma, 1980; Pakrasi \& Dey, 1982; Racowsky \& Biggers, 1983; Harper et al., 1983; Kasamo, 1985; Kasamo et al., 1986), and of other species (Shemesh et al., 1979; Marcus, 1981; Lewis et al., 1982; Hyland et al., 1982; Davis et al., 1983; Hwang et al., 1988). Many of these studies relied on radioimmuno-assay of PGs released into the medium during in-vitro culture or of PGs found in the blastocyst itself. Such data

*Present address: Department of Chemistry, Felmley Hall, Illinois State University, Normal, Illinois 61761, USA. 
do not provide direct evidence for de-novo synthesis of PGs by the blastocysts, since they could be measuring PGs accumulated from and then released into the external environment. It is known that rabbit blastocysts can accumulate PGs from their environment, and that this facilitated diffusion is non-saturable (Jones \& Harper, 1984; Jones et al., 1985).

Indirect evidence for the synthesis of PGs by blastocysts has been provided by experiments in which blastocysts cultured in the presence of cyclooxygenase inhibitors subsequently failed to hatch (Biggers et al., 1978, 1981; Hurst \& MacFarlane, 1981). Only a few studies, however, have demonstrated direct conversion of radiolabelled substrate to radiolabelled product. In order to demonstrate conversion of exogenous $\left[{ }^{3} \mathrm{H}\right]$ arachidonic acid by either mouse or rabbit blastocysts, Racowsky \& Biggers (1983) prelabelled the phospholipid pool with radiolabelled arachidonic acid for $4 \mathrm{~h}$, and then induced release, with a calcium ionophore, of the incorporated, labelled arachidonic acid, which was converted to PGE-2, PGD-2, PGF-2 $\alpha$ and thromboxane B-2. Lewis $e t$ al. (1982) were, however, able to demonstrate direct conversion of $\left[{ }^{3} \mathrm{H}\right]$ arachidonic acid to PGE-2, PGF-2 $\alpha$ and 13,14-dihydro-15-keto-PGF-2 $\alpha$ by late stage bovine blastocysts. Kasamo (1985) and Kasamo et al. (1986) showed that conversion of $\left[{ }^{14} \mathrm{C}\right]$ arachidonic acid to radiolabelled PGF-2 $\alpha$, but not to PGE-2, was achieved in $1 \mathrm{~h}$ by Day- 6 rabbit blastocysts in the presence of $10^{-3} \mathrm{M}-$ adrenaline.

In preliminary studies, we were unsuccessful in obtaining conversion of radiolabelled arachidonic acid to PGs by Day-6 rabbit blastocysts with any consistency. The present paper describes our recent experiments, in which positive and repeatable results have been achieved by the addition of ethylene diamine tetra-acetic acid (EDTA) to the incubation medium. A preliminary account of this material has been presented (Harper et al., 1987). The results obtained with incubations including atropine and carbachol are also reported, since previous studies had indicated the presence of specific cholinergic - muscarinic binding sites on Day- 6 rabbit blastocysts (Jones \& Harper, 1985). Activation of such sites would be expected to increase the release of endogenous substrate from phospholipid pools, and thus reduce utilization of exogenous substrate.

\section{Materials and Methods}

Materials. $\left[5,6,8,9,11,12,14,15-{ }^{3} \mathrm{H}\right]$ Arachidonic acid was obtained from Amersham Corporation (Arlington Heights, IL, USA), and had a specific activity of $218 \mathrm{Ci} / \mathrm{mmol}$. $\left[5,6,8,11,12,14,15-(\mathrm{n})-{ }^{3} \mathrm{H}\right] \mathrm{PGE}-2$ (sp. act. $\left.160 \mathrm{Ci} / \mathrm{mmol}\right)$ and $\left[5,6,8,9,11,12,14,15-(\mathrm{n})-{ }^{3} \mathrm{H}\right] \mathrm{PGF}-2 \alpha$ (sp. act. $180 \mathrm{Ci} / \mathrm{mmol}$ ) were also obtained from Amersham Corporation. These isotopes were stored in ethanol at $-20^{\circ} \mathrm{C}$. To each incubation tube, $10 \mu \mathrm{l}$ of the stock $\left[{ }^{3} \mathrm{H}\right]$ arachidonic acid were added, so that $10 \mu \mathrm{Ci}$ could be added to the $1 \mathrm{ml}$ incubation volume at a final concentration of $1 \%$ ethanol. A similar concentration of ethanol was added to all control tubes. All experiments were conducted using Krebs-Ringerbicarbonate (KRB) buffer, pH 7.4 (119 mm- NaCl, $4.7 \mathrm{~mm}-\mathrm{KCl}, 1.2 \mathrm{~mm}-\mathrm{KH}_{2} \mathrm{PO}_{4}, 1.2 \mathrm{~mm}-\mathrm{MgSO}_{4}, 25 \mathrm{~mm}-\mathrm{NaHCO}_{3}$, $1.7 \mathrm{~mm}^{-\mathrm{CaCl}_{2}}$, and $5 \mathrm{~mm}$-glucose). In some experiments calcium was omitted from the buffer. Incubations were done in polypropylene tubes (Falcon, Oxnard, CA, USA). Human chorionic gonadotrophin (hCG) was purchased from Ayerst Laboratories (New York, NY, USA), pentobarbitone sodium solution from Fort Dodge Laboratories, Inc. (Fort Dodge, IA, USA), ethylene diamine tetra-acetic acid (EDTA), ethyleneglycol-bis-( $\beta$ aminoethylether) $\mathrm{N}, \mathrm{N}, \mathrm{N}^{1}, \mathrm{~N}^{1}$-tetra-acetic acid (EGTA), and indomethacin, pig follicle stimulating hormone (FSH), atropine, carbachol, quinacrine and radioinert arachidonic acid were from Sigma Chemical Company (St Louis, MO, USA) and Flo-Scint ${ }^{(B}$ II scintillation cocktail was from Radiomatic Instruments \& Chemical Co. (Tampa, FL, USA). All chromatography solvents were of h.p.l.c. quality purchased from various vendors.

Animals. The mature female rabbits of the New Zealand White-Cambridge strain ( $>3.5 \mathrm{~kg})$ were obtained from Penn Acres (Wimberley, TX, USA) and were caged individually in a controlled environment with a photoperiod of $14 \mathrm{~h}$ light per $24 \mathrm{~h}$. Water and food were supplied ad libitum. Animals in oestrus were selected after examination for vaginal engorgement, and injected with pig FSH subcutaneously (s.c.; $0.5 \mathrm{U} /$ injection) twice a day on Days $-3,-2$ and -1 (Mukherjee et al., 1978) to induce superovulation. On Day 0 , the donor rabbits were inseminated with $0.5 \mathrm{ml}$ of a mixed sperm suspension collected, via an artificial vagina, from fertile bucks immediately before use and diluted 1:1 with KRB buffer. After insemination, the donor animals were injected intravenously (i.v.) with 50 i.u. hCG. Usually groups of 5-6 animals were inseminated at one time and then killed by an overdose of pentobarbitone sodium on Day 6 of pregnancy, i.e. at $144 \mathrm{~h}$ after hCG injection. The uteri were rapidly removed, trimmed of fat, separated into two horns and washed free of blood. The separate horns were flushed gently using $10 \mathrm{ml}$ ice-cold KRB buffer into $60 \times 15 \mathrm{~mm}$ Falcon Petri dishes. The blastocysts were then washed 3 times with buffer. 
Incubations. All blastocysts of normal appearance were pooled, and then 7-11 blastocysts were selected randomly from the pool and placed in polypropylene tubes in $1 \mathrm{ml}$ of the same buffer, which had been previously bubbled with $95 \% \mathrm{O}_{2}: 5 \% \mathrm{CO}_{2}$. The blastocysts were then ruptured with a dissecting needle and gently vortexed to ensure collapse of the blastocoele. The tubes were incubated at $37^{\circ} \mathrm{C}$ for periods ranging from 1 to $3 \mathrm{~h}$. In each experiment one control tube contained $\left[{ }^{3} \mathrm{H}\right]$ arachidonic acid $(10 \mu \mathrm{Ci}=45.9 \mathrm{pmol})$ in buffer without blastocysts. The other tubes all received blastocysts and $10 \mu \mathrm{Ci}\left[{ }^{3} \mathrm{H}\right]$ arachidonic acid. In some experiments calcium was omitted from the incubation buffer, and in others EDTA was also omitted. In most experiments EDTA at a final concentration of $10 \mathrm{~mm}$ (dissolved in buffer) was included. In some experiments atropine or carbachol at a final concentration of $0.15 \mathrm{~mm}$ dissolved in buffer or radioinert arachidonic acid at a final concentration of $10 \mu \mathrm{g} / \mathrm{ml}$ dissolved in ethanol was added.

Extraction and h.p.l.c. After incubation, the excess unmetabolized $\left[{ }^{3} \mathrm{H}\right]$ arachidonic acid was extracted from the blastocysts and medium combined by the addition of $4 \mathrm{ml}$ hexane. The mixture was vortexed, phased and the hexane discarded. The PGs were extracted from the aqueous phase by two additions of 4 volumes of ethyl acetate (analytical grade, redistilled) after acidification to $\mathrm{pH} 4.5$ with $1 \mathrm{ml}$ cold $0.5 \mathrm{M}$-acetate buffer. These extracts were pooled, dried under a stream of nitrogen gas, and resuspended in $0.5 \mathrm{ml}$ h.p.l.c. column solvent (water:acetonitrile:glacial acetic acid, 719:280:1 by vol.) The samples $(0.4 \mathrm{ml}$ ) were applied to a Microsorb $\mathrm{Cl} 8$ column (Rainin Instrument Co., Inc., Woburn, MA, USA) with a Whatman CO/Pell octadecylsilyl silica guard column (Whatman Chemical Separation, Inc., Clifton, NJ, USA) attached to an h.p.l.c. system (LDC/Milton Roy, Riviera Beach, FL, USA), which was fitted with a sample injector (model no. 7120, Rheodyne, Inc., Cotati, CA, USA). The PGs were eluted over a 50 min period by pumping the h.p.l.c. column solvent at $0.75 \mathrm{ml} / \mathrm{min}$ (Eling et al., 1980). This solvent mix did not elute arachidonic acid, although some low levels of radioactivity were seen in elutions of control samples, presumably representing radioactive decay products of the $\left[{ }^{3} \mathrm{H}\right]$ arachidonic acid. To elute arachidonic acid, a solvent mix of water:acetonitrile: glacial acetic acid (49:950:1, by vol.) was needed.

Evaluation of radioactivity. The eluate from the h.p.l.c. was then pumped through a Radiomatic Flo-One model HS liquid scintillation counter with a $2.5 \mathrm{ml}$ counting cell at a flow rate of $3 \mathrm{ml} / \mathrm{min}(0.75 \mathrm{ml} / \mathrm{min} \mathrm{h.p.l.c.} \mathrm{eluate} \mathrm{plus}$ $\left.2.25 \mathrm{ml} / \mathrm{min} \mathrm{Flo-Scint}{ }^{\oplus} \mathrm{II}\right)$.

The data output from the counter was then passed through an A to D interface to a PMC 101A microcomputer connected to a Qume terminal and stored on floppy disks for further processing using the Radiomatic FlB CU software program. This program records the radioactive emissions for each 6-sec interval, and graphs them on an interval or integrated scale to show the percentage of the total radioactivity recovered in each individual run in each peak. Background subtract was set at 100 c.p.m., and more than 1000 c.p.m. was required to indicate a separate peak. Efficiency of counting was determined to be $34.9 \%$. Values (d.p.m.) shown in the figures have been calcuiated allowing for efficiency of counting, but not for losses on the column (see below). Losses over a $\mathrm{l}-\mathrm{h}$ period of incubation due to adherence of $\left[{ }^{3} \mathrm{H}\right]$ arachidonic acid to the plastic tubes were $<2 \%$, even though significant adherence to glass can occur (Samples et al., 1988). Losses during extraction were also minimal. However, when these experiments were completed, it was determined (D. R. Samples \& J. T. Herlihy, personal communication) that loading more than $250 \mu 1$ into the sample loop of an injector with a $0.5 \mathrm{ml}$ volume caused a significant loss of sample through the overflow outlet. Since we had routinely loaded $0.4 \mathrm{ml}$ onto the column, we retrospectively determined that our average loss was $20.0 \%$ and have corrected all values shown in the tables for this loss.

An algorithm written by one of us (D.S.W.) permitted the 6-sec c.p.m. values in each control run to be subtracted from the same 6-sec increments in all the other experimental runs in a single experiment. The new files thus created were stored and could be reprocessed in the usual way by the Radiomatic program. For statistical analysis, peaks were allotted to the 2-min segment of the run in which the integrated mid-point of the peak occurred. In each experiment at least one chromatographic run was made with the radioactive standards, $\left[{ }^{3} \mathrm{H}\right] \mathrm{PGF}-2 \alpha$ and $\left[{ }^{3} \mathrm{H}\right] \mathrm{PGE}-2$. A representative chromatogram of such standards is shown in Fig. 1. Owing to the use of new h.p.l.c. columns and fresh running buffer the time of elution for the standards varied slightly between different experiments; therefore all peaks in experimental chromatograms were adjusted by the same amount that the peaks for the standards in the same run had to be adjusted to conform to previous runs.

Statistical analyses. The mean percentages of radioactivity in each 2-min time period were calculated for all experimental treatments, i.e. 3 treatments (no drug, atropine and carbachol), 3 times of incubation $(1,2$ and $3 \mathrm{~h}$ ) and 18 sampling times during the h.p.l.c. run ( $<8,8-40$ in 2 min segments and $>40 \mathrm{~min}$ ). To identify the appearance of peaks over time the data were subjected to analysis of variance (ANOVA) and Student-Newman-Keuls (SNK) multiple range test. A preliminary examination of the distributions in the cells of this $3 \times 3 \times 18$ model indicated that the means and standard errors were highly correlated $(r=0.9, P<0.001)$, which indicated that a transformation of the data was necessary before performing the ANOVA. The common logarithmic transformation $\left[\log _{10}(x+1)\right]$ resulted in uncorrelated means and standard errors. A 3-way ANOVA was then performed on the log-transformed values, and indicated that the main effects of drug $(P<0.021)$, incubation time $(P<0.015)$ and sampling increment $(P<0.001)$ were significant. However, the only interaction term that was marginally significant was drug with sampling increment $(P<0.072)$. This interaction result suggests that the differences between increments were not consistent for each drug, and reduction of the model to identify the differences was necessary. Since the number of sampling times in each run without significant peaks was large, the data were reduced to the three peak percentage values $(\mathrm{I}=\mathrm{PGF}-2 \alpha, \mathrm{II}=\mathrm{PGE}-2$ and III $=$ unidentified metabolite) and remainder ( $\%$ of all other d.p.m. in the run) and the analysis re-run. 


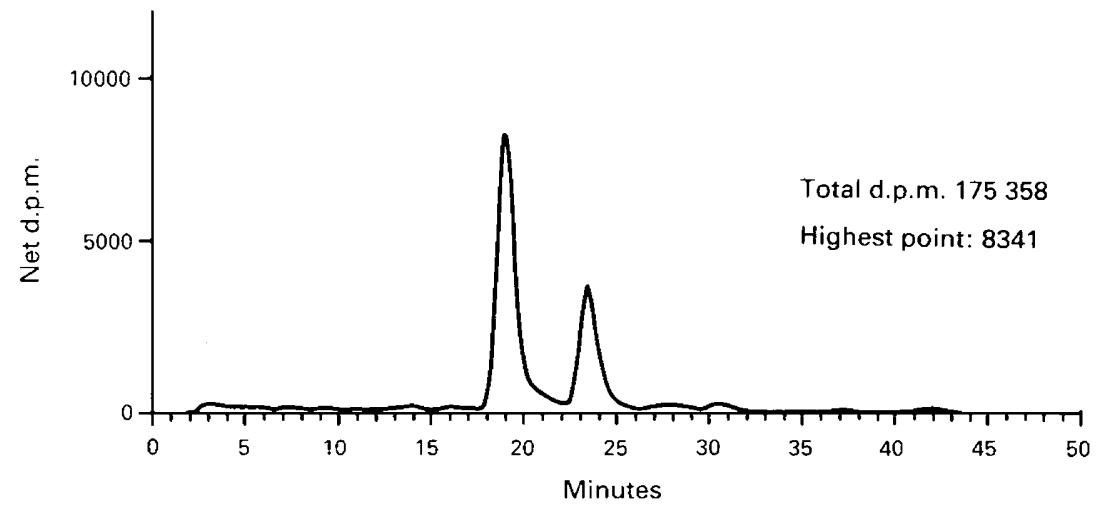

Fig. 1. Chromatogram of $\left[{ }^{3} \mathrm{H}\right]$ PGF-2 $\alpha$ (Peak I) and $\left[{ }^{3} \mathrm{H}\right]$ PGE-2 (Peak II) standards.

The only significant factor in this 3-way ANOVA was peak $(P<0.0001)$. Drug $(P=0.54)$ and time of incubation $(P=0.66)$ were not significant. No interactions were significant. One-way ANOVA and SNK tests were then done for each of the 9 separate drug/time intervals (see Table 4 for significant differences). Comparisons between means of d.p.m./blastocyst and percentages of total radioactivity recovered in other tables were also made by SNK tests.

\section{Results}

\section{Effect of EDTA and calcium}

In the absence of EDTA, there was little or no increase in radioactivity above blank values in any of the many experiments conducted with Day-6 blastocysts. Figure 2(a) shows the results of a 1-h incubation of blastocysts in a representative experiment in the absence of EDTA. This chromatogram is representative for those at all time intervals ( 1,2 or $3 \mathrm{~h}$ incubations). The chromatogram in Fig. 2(a) can be contrasted directly with that of a 1-h incubation in the presence of 10 mM-EDTA (Fig. 2b), since both were from the same experiment. In one experiment with a $2-\mathrm{h}$ incubation period, the effects of different concentrations of EDTA were examined. PG synthesis was similar at concentrations of 10 to $40 \mathrm{~mm}$, but reduced at $5 \mathrm{~mm}$ (data not shown). Unless otherwise specified, $10 \mathrm{~mm}$-EDTA was included in all subsequent experiments.

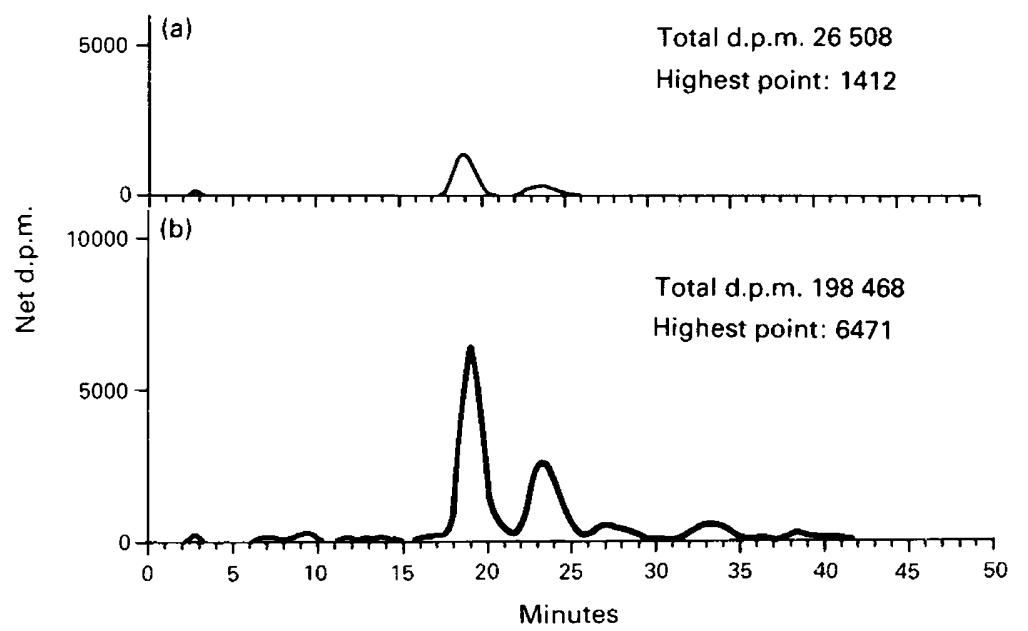

Fig. 2. Reprocessed chromatogram of incubation of $\left[{ }^{3} \mathrm{H}\right]$ arachidonic acid for $1 \mathrm{~h}$ with Day- 6 blastocysts in (a) the absence of EDTA, and (b) the presence of $10 \mathrm{~mm}$-EDTA. 
To study the contribution of endogenous arachidonic acid to the substrate pool, a series of experiments was done in which calcium and/or EDTA was included or omitted from the incubation medium. Two experiments were done at $1 \mathrm{~h}$, and one each at 2 and $3 \mathrm{~h}$. No differences were seen among incubation times, and so only the pooled data are shown in Table 1 . The presence or absence of calcium in the medium was immaterial (data not shown). Significant PG synthesis was only achieved in the presence of EDTA. In the absence of EDTA very few d.p.m. remained after blank subtraction, whereas when EDTA was present the remaining 30.8\% of d.p.m. (after blank subtraction) were in peaks that co-eluted with PGs. Similarly, the mean d.p.m. observed in the PG peaks, in the presence of EDTA, was almost 16-fold greater (on a per blastocyst basis) than in the absence of EDTA. Apparently, although only very small amounts of radiolabelled products were synthesized in the absence of EDTA, significantly more radioactivity was in the peak eluting with PGF- $2 \alpha$ and correspondingly less in that for PGE-2 than when EDTA was present. In the presence of EDTA, the radioactivity was almost equally distributed between PGF- $2 \alpha$ and PGE-2. Pilot experiments showed that addition of $10 \mathrm{~mm}$-EGTA to the incubation medium was much less effective than EDTA in permitting utilization of the radiolabelled substrate (data not shown). Quinacrine (0.1 mM), an inhibitor of phospholipase $A_{2}$ activity (Albert \& Snyder, 1983), added to the incubation medium was without effect (data not shown).

Table 1. Effect of EDTA (10 mM) on synthesis of prostaglandins by Day-6 rabbit blastocysts

\begin{tabular}{|c|c|c|c|c|c|}
\hline \multirow[b]{2}{*}{ Treatment } & \multirow[b]{2}{*}{$n$} & \multirow{2}{*}{$\begin{array}{l}\text { \% of } \\
\text { sample d.p.m. in } \\
\text { chromatogram } \\
\text { after blank } \\
\text { subtraction }\end{array}$} & \multirow{2}{*}{$\begin{array}{c}\text { Total } \\
\text { d.p.m./blastocyst } \\
\text { remaining } \\
\text { after blank } \\
\text { subtraction }\end{array}$} & \multicolumn{2}{|c|}{$\begin{array}{l}\% \text { d.p.m. } \\
\text { remaining in peaks }\end{array}$} \\
\hline & & & & PGF- $2 \alpha$ & PGF-2 \\
\hline No EDTA & 6 & $2 \cdot 6 \pm 0 \cdot 4$ & $814 \pm 202$ & $76 \cdot 6 \pm 5 \cdot 8$ & $20 \cdot 2 \pm 4 \cdot 6$ \\
\hline With EDTA & 6 & $30 \cdot 8 \pm 3 \cdot 3^{* * *}$ & $12740 \pm 1173^{* * *}$ & $32 \cdot 5 \pm 3 \cdot 3^{* * *}$ & $46 \cdot 2 \pm 2 \cdot 4^{* * *}$ \\
\hline
\end{tabular}

$n=5$ pools of 10 blastocysts and 1 pool of 8 blastocysts. Incubation times ranged from 1 to $3 \mathrm{~h}$ at $37^{\circ} \mathrm{C}$.

The final d.p.m. in each sample chromatogram were determined by subtracting the 6-sec values in the blank run $\left(\left[{ }^{3} \mathrm{H}\right]\right.$ arachidonic acid incubated without blastocysts) from the 6-sec values in the experimental run. The remaining d.p.m. were then integrated into peaks using the Radiomatic Flo-One algorithm (peak > 1000 d.p.m.), and adjusted according to the elution time of the radiolabelled standards.

***P $<0.001$ compared with no EDTA.

\section{Effect of indomethacin}

To verify that the radioactivity appearing in the chromatograms was due to cyclooxygenasemodulated synthesis of PGs, some experiments were conducted in which $100 \mu \mathrm{g}$ indomethacin $/ \mathrm{ml}$ in ethanol was present. The final concentration of ethanol was $2 \%$, but the same concentration was added to the control tubes. The summarized data from these experiments are shown in Table 2 . As with the EDTA experiments, there was no statistical difference between the 1- and 2-h incubation times, and consequently the data for both times were pooled. In the presence of this high dose of indomethacin conversion of $\left[{ }^{3} \mathrm{H}\right]$ arachidonic acid to prostanoids was inhibited significantly and 11 times more d.p.m. per blastocyst were seen in its absence. Unlike the experiments in the absence of EDTA, however, the percentage of label in the presence of indomethacin was almost equally distributed between the PGF- $2 \alpha$ and PGE- 2 peaks. This provides evidence that indomethacin was suppressing synthesis of PGs.

\section{Effect of radioinert arachidonic acid}

When radioinert arachidonic acid at $10 \mu \mathrm{g} / \mathrm{ml}(\sim 720$-fold excess based on specific activity calculations) was added to incubations in addition to the $10 \mu \mathrm{Ci}\left[{ }^{3} \mathrm{H}\right]$ arachidonic acid, synthesis of 
averaging about 30000 . The percentages of total label applied to the h.p.l.c. column which were recovered over and above the blank value were slightly greater than $50 \%$ of the sample d.p.m., and also did not differ between incubation times.

Table 4. Effect of time of culture on the percentage (mean \pm s.e.m.) of ${ }^{3} \mathrm{H}$-labelled metabolites produced by Day- 6 rabbit blastocysts (after subtraction of blank values)

\begin{tabular}{|c|c|c|c|c|c|c|c|c|}
\hline \multirow[b]{2}{*}{ Treatment } & \multirow{2}{*}{$\begin{array}{l}\text { Incubation } \\
\text { time (h) }\end{array}$} & \multirow[b]{2}{*}{$n$} & \multicolumn{3}{|c|}{ Peaks } & \multirow[b]{2}{*}{ Remainder } & \multirow{2}{*}{$\begin{array}{c}\text { d.p.m./ } \\
\text { blastocyst }\end{array}$} & \multirow{2}{*}{$\begin{array}{c}\% \text { of total } \\
\text { d.p.m. } \\
\text { blastocyst }\end{array}$} \\
\hline & & & I & II & III & & & \\
\hline \multirow[t]{3}{*}{ Control } & 1 & 10 & $\begin{array}{c}36 \cdot 0 \pm \\
5 \cdot 1^{2}\end{array}$ & $\begin{array}{c}33 \cdot 1 \pm \\
2 \cdot 6^{2}\end{array}$ & $\begin{array}{l}9 \cdot 3 \pm \\
2 \cdot 7^{6}\end{array}$ & $\begin{array}{r}21 \cdot 5 \pm \\
6 \cdot 3^{3 \cdot .6}\end{array}$ & $\begin{array}{c}29753 \pm \\
5767\end{array}$ & $\begin{array}{c}51 \cdot 1 \pm \\
6.7\end{array}$ \\
\hline & 2 & 7 & $\begin{array}{c}37 \cdot 1 \pm \\
9 \cdot 9^{2}\end{array}$ & $\begin{array}{r}28.9 \pm \\
3.9^{\mathrm{a}}\end{array}$ & $\begin{array}{c}13 \cdot 3 \pm \\
3 \cdot 6^{\mathrm{a}}\end{array}$ & $\begin{array}{c}20 \cdot 7 \pm \\
7 \cdot 4^{2}\end{array}$ & $\begin{array}{c}29090 \pm \\
8055\end{array}$ & $\begin{array}{c}51 \cdot 6 \pm \\
7.3\end{array}$ \\
\hline & 3 & 5 & $\begin{array}{r}34 \cdot 0 \pm \\
6 \cdot 4^{4}\end{array}$ & $\begin{array}{c}33 \cdot 3 \pm \\
1 \cdot 8^{2}\end{array}$ & $\begin{array}{c}16 \cdot 0 \pm \\
3 \cdot 5^{ \pm}\end{array}$ & $\begin{array}{c}13 \cdot 9 \pm \\
5 \cdot 0^{2}\end{array}$ & $\begin{array}{l}48738 \pm \\
26834\end{array}$ & $\begin{array}{l}56 \cdot 7 \pm \\
10 \cdot 7\end{array}$ \\
\hline \multirow[t]{3}{*}{$\begin{array}{l}\text { Atropine } \\
(0 \cdot 15 \mathrm{~mm})\end{array}$} & 1 & 5 & $\begin{array}{c}40 \cdot 3 \pm \\
7 \cdot 7^{ \pm}\end{array}$ & $\begin{array}{c}30 \cdot 4 \pm \\
1 \cdot 3^{ \pm}\end{array}$ & $\begin{array}{l}9 \cdot 3 \pm \\
3 \cdot 3^{\mathrm{b}}\end{array}$ & $\begin{array}{r}20 \cdot 0 \pm \\
5 \cdot 7^{20 . b}\end{array}$ & $\begin{array}{r}21236 \pm \\
8901\end{array}$ & $\begin{array}{l}42.5 \pm \\
11.9\end{array}$ \\
\hline & 2 & 6 & $\begin{array}{c}31.9 \pm \\
6.1^{1}\end{array}$ & $\begin{array}{r}29 \cdot 8 \pm \\
4 \cdot 3^{\mathrm{a}}\end{array}$ & $\begin{array}{c}14 \cdot 5 \pm \\
2 \cdot 4^{\mathrm{a}}\end{array}$ & $\begin{array}{l}23 \cdot 8 \pm \\
10 \cdot 0^{\mathrm{a}}\end{array}$ & $\begin{array}{r}20640 \pm \\
6529\end{array}$ & $\begin{array}{c}45.8 \pm \\
9.0\end{array}$ \\
\hline & 3 & 6 & $\begin{array}{c}40 \cdot 2 \pm \\
4 \cdot 8^{2}\end{array}$ & $\begin{array}{c}32 \cdot 5 \pm \\
1 \cdot 4^{2}\end{array}$ & $\begin{array}{c}13 \cdot 9 \pm \\
2 \cdot 4^{\mathrm{k}}\end{array}$ & $\begin{array}{c}13 \cdot 3 \pm \\
3 \cdot 6^{6}\end{array}$ & $\frac{20819 \pm}{3685} \pm$ & $\begin{array}{c}48 \cdot 8 \pm \\
5 \cdot 2\end{array}$ \\
\hline \multirow[t]{3}{*}{$\begin{array}{l}\text { Carbachol } \\
(0.15 \mathrm{~mm})\end{array}$} & 1 & 5 & $\begin{array}{l}51 \cdot 8 \pm \\
10 \cdot 2^{2}\end{array}$ & $\begin{array}{r}35 \cdot 3 \pm \\
5 \cdot 8^{ \pm}\end{array}$ & $\begin{array}{l}5 \cdot 2 \pm \\
1 \cdot 3^{b}\end{array}$ & $\begin{array}{l}7.8 \pm \\
3.7^{6}\end{array}$ & $\begin{array}{c}13059 \pm \\
2224\end{array}$ & $\begin{array}{c}23 \cdot 2 \pm \\
3 \cdot 8\end{array}$ \\
\hline & 2 & 5 & $\begin{array}{r}33 \cdot 5 \pm \\
6 \cdot 3^{2, b}\end{array}$ & $\begin{array}{c}40 \cdot 1 \pm \\
4 \cdot 2^{2}\end{array}$ & $\begin{array}{l}9 \cdot 6 \pm \\
1 \cdot 3^{\circ}\end{array}$ & $\begin{array}{c}17 \cdot 1 \pm \\
5 \cdot 0^{6}\end{array}$ & $\begin{array}{r}18075 \\
4999\end{array}$ & $\begin{array}{c}33 \cdot 3 \\
5 \cdot 4\end{array}$ \\
\hline & 3 & 5 & $\begin{array}{c}35 \cdot 3 \pm \\
4 \cdot 1^{2}\end{array}$ & $\begin{array}{c}44 \cdot 5 \pm \\
3 \cdot 0^{2}\end{array}$ & $\begin{array}{l}8 \cdot 2 \pm \\
3 \cdot 7^{b}\end{array}$ & $\begin{array}{c}12 \cdot 0 \pm \\
3 \cdot 6^{\mathrm{b}}\end{array}$ & $\begin{array}{c}15419 \\
3405\end{array}$ & $\begin{array}{c}30 \cdot 0 \pm \\
8 \cdot 2\end{array}$ \\
\hline
\end{tabular}

$n=$ no. of incubation tubes with pools of 7-10 blastocysts/tube.

The final d.p.m. in each sample chromatogram were determined by subtracting the 6-sec values in the blank run $\left(\left[{ }^{3} \mathrm{H}\right]\right.$ arachidonic acid incubated without blastocysts) from the 6-sec values in the experimental run. The remaining d.p.m. were then integrated into peaks using the Radiomatic Flo-One algorithm (peak $>1000$ d.p.m.), and adjusted according to the elution time of the radiolabelled standards.

Values with different superscripts in each row differ significantly i.e. $\mathrm{a}$ is different from $\mathrm{b}$, but not from $\mathrm{a}, \mathrm{b}(P<0.05)$.

Incubations with atropine and carbachol. In the presence of EDTA, very similar results were obtained when $0.15 \mathrm{~mm}$-atropine (dissolved in buffer) was added to the incubation (Table 4). Three peaks were again observed. Peaks I and II did not differ between themselves, but Peak III was significantly lower than these at the 1 - and 3 -h incubation times $(P<0.05)$. A representative chromatogram for a 1-h incubation is shown in Fig. 3(a). This should be compared with Fig. 2(b), and Fig. 3(b) (see below). The d.p.m./blastocyst averaged $\sim 20000$, and only about $45 \%$ of the radioactivity above background remained in these experiments. These values are somewhat lower, but not significantly so, than those observed in the control experiments (see also Table 4).

An essentially similar result was seen with addition of $0.15 \mathrm{~mm}$-carbachol instead of atropine (Table 4). Again most of the radioactivity was observed in the same three peaks, although Peaks I and II were significantly higher than Peak III at all three times $(P<0.05)$ (Fig. 3b). There was also a tendency towards lower incorporation of radioactivity/blastocyst than for control or atropinetreated ones, but these differences were not significant (SNK test).

To ensure that the presence of EDTA was not obscuring the action of these compounds, the previous series of experiments was repeated in a limited study with EDTA absent from the incubation medium (Table 5). In the absence of EDTA, neither atropine nor carbachol had any effect on the total conversion of $\left[{ }^{3} \mathrm{H}\right]$ arachidonic acid to products greater than control levels. There was also no effect on the relative levels of the various $\mathrm{PG}$ products synthesized. In the absence of 


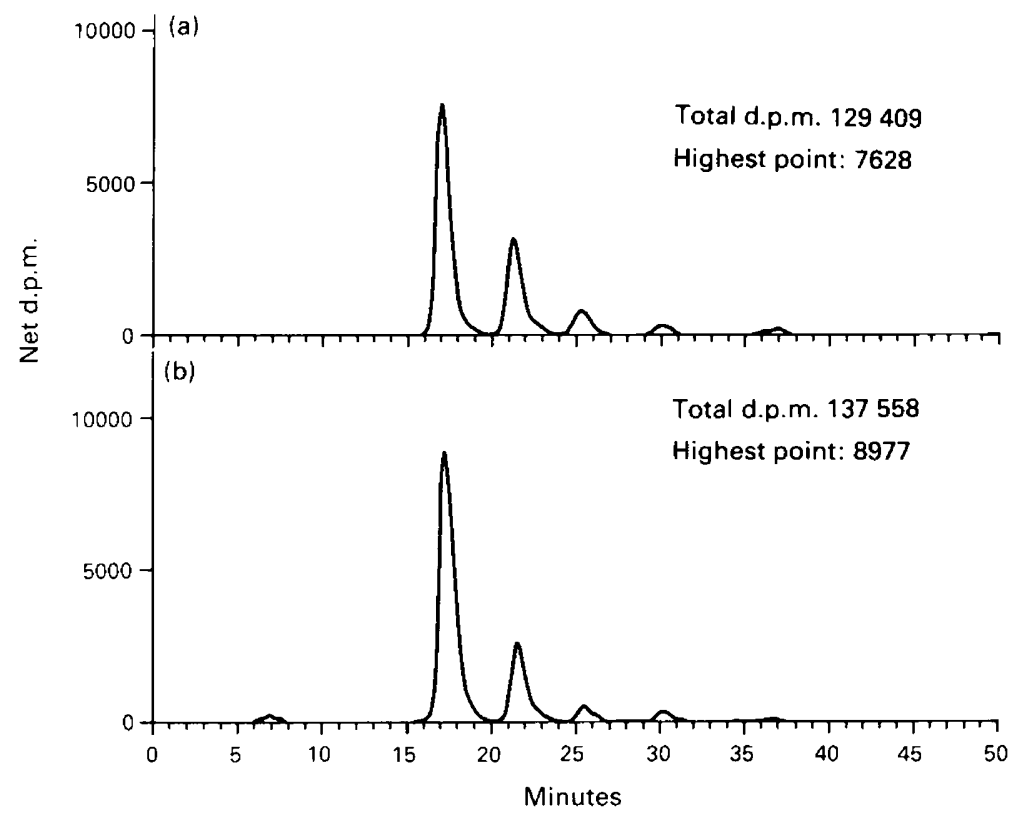

Fig. 3. Reprocessed chromatogram of incubation of $\left[{ }^{3} \mathrm{H}\right]$ arachidonic acid for $1 \mathrm{~h}$ with Day- 6 blastocysts in the presence of (a) $0.15 \mathrm{~mm}$-atropine and $10 \mathrm{~mm}$-EDTA, and (b) $0.15 \mathrm{~mm}$ carbachol and $10 \mathrm{~mm}$-EDTA.

EDTA the d.p.m. values for products shown by h.p.l.c. ranged from 10.4 to $16 \cdot 6 \%$ of the level seen in the presence of EDTA, regardless of the presence or absence of atropine or carbachol. Therefore, it is the presence or absence of EDTA which determines how much $\left[{ }^{3} \mathrm{H}\right]$ arachidonic acid is converted to $\left[{ }^{3} \mathrm{H}\right]$ prostanoids, and the presence or absence of atropine or carbachol is without effect.

Table 5. Effect of EDTA on stimulation by atropine and carbachol of synthesis of prostaglandins by Day- 6 rabbit blastocysts

\begin{tabular}{|c|c|c|c|c|c|}
\hline \multirow[b]{2}{*}{ Treatment } & \multirow[b]{2}{*}{$n$} & \multirow{2}{*}{$\begin{array}{l}\% \text { of sample } \\
\text { d.p.m. in chromatogram } \\
\text { after blank subtraction }\end{array}$} & \multirow{2}{*}{$\begin{array}{l}\text { Total d.p.m./blastocyst } \\
\text { remaining after blank } \\
\text { subtraction }\end{array}$} & \multicolumn{2}{|c|}{$\begin{array}{l}\% \text { d.p.m. remaining } \\
\text { in peaks }\end{array}$} \\
\hline & & & & PGF- $2 \alpha$ & PGF-2 \\
\hline $\begin{array}{l}\text { Control } \\
+ \text { EDTA }\end{array}$ & 2 & $50 \cdot 6$ & 43052 & 56.91 & $25 \cdot 03$ \\
\hline $\begin{array}{l}\text { Control } \\
\text {-EDTA } \\
\text { Atropine }\end{array}$ & 1 & $11 \cdot 8$ & 4470 & $78 \cdot 15$ & $21 \cdot 85$ \\
\hline $\begin{array}{l}\text {-EDTA } \\
\text { Carbachol }\end{array}$ & 2 & $16 \cdot 4$ & 5562 & $70 \cdot 40$ & $26 \cdot 46$ \\
\hline -EDTA & 2 & $15 \cdot 3$ & 6994 & $69 \cdot 45$ & $25 \cdot 32$ \\
\hline
\end{tabular}

Incubation for $1 \mathrm{~h}$ at $37^{\circ} \mathrm{C} . n=$ pools of 10 blastocysts.

The final d.p.m. in each sample chromatogram were determined by subtracting the 6-sec values in the blank run $\left(\left[{ }^{3} \mathrm{H}\right]\right.$ arachidonic acid incubated without blastocysts) from the 6-sec values in the experimental run. The remaining d.p.m. were then integrated into peaks using the Radiomatic Flo-One algorithm (peak > 1000 d.p.m.), and adjusted according to the elution time of the radiolabelled standards. 


\section{Discussion}

The results of the present experiments are in general agreement with those conducted previously. Under appropriate circumstances synthesis of PGs can be demonstrated, but the conversion of exogenous substrate is extremely limited unless mobilization of endogenous substrate is prevented. The fact that the presence or absence of calcium in the incubation buffer was without effect on the response to EDTA, and that EGTA was not as effective as EDTA, suggests that the action of EDTA is not simply due to chelation of calcium. The lack of effect of quinacrine indicates that EDTA does not work via an inhibition of phospholipase activity. The exact mode of action of EDTA is unclear, but may be modulated through some inhibition of release of endogenous arachidonic acid, perhaps by a membrane stabilizing action.

The inhibitory effect of indomethacin suggests that the conversion of label to products which eluted under the same conditions as prostanoids is enzymically driven. However, the dose of indomethacin used was very high, and we and others have shown that PG transport can be markedly affected by such high doses (Bito et al., 1976; Melendez \& Reyes, 1982; Jones \& Harper, 1984; Jones et al., 1986). Previous experiments using radiolabelled arachidonic acid had indicated that rabbit blastocysts can synthesize PGE-2, PGF-2 $\alpha$, PGD-2 and thromboxane B-2 (Racowsky \& Biggers, 1983) and/or only PGF-2 $\alpha$ as well as some unidentified products (Kasamo et al., 1986). In the present experiments, we definitely identified PGE-2 and PGF-2 $\alpha$, and detected a third peak, which could be PGD-2 or a 15-keto PG metabolite. This agrees well with previously reported data on RIA measurements of PGs released from or found in rabbit blastocysts (Dey et al., 1980; Sharma, 1980; Pakrasi \& Dey, 1982; Harper et al., 1983), with the exception that no 6-keto-PGF-1 $\alpha$ or thromboxane B-2 was observed. Hwang et al. (1988) showed that cattle embryos at Day 15 to 17 (implantation occurs after Day 18) synthesize PGE-2, PGF-2 $\alpha$ and PGI-2 from radiolabelled arachidonic acid. Using RIA, we have measured very low levels of 6-keto-PGF-1 $\alpha$ (the stable metabolite of PGI-2) in Day-6 rabbit blastocysts, i.e. $0.04 \pm 0.007 \mathrm{ng}$ /blastocyst (Jones \& Harper, 1988). Such low levels may not be detectable by h.p.l.c., although small traces of radioactivity above background were seen in many of the radiochromatograms.

In immature pig oocytes arachidonic acid constituted $\sim 7 \%$ of the total fatty acids, and was concentrated mainly in triacylglycerol and phospholipids and as free fatty acids (Homa et al., 1986). Racowsky \& Biggers (1983) found that, in rabbit blastocysts, $\left[{ }^{3} \mathrm{H}\right]$ arachidonic acid was incorporated mainly into phosphatidylcholine, phosphatidylethanolamine and neutral lipids. Upon treatment with a calcium ionophore, $\left[{ }^{3} \mathrm{H}\right]$ arachidonic acid released from these sources was converted into approximately $1.5 \mathrm{fmol}$ of PGF-2 $\alpha$, PGE-2 and thromboxane B-2/blastocyst in $1 \mathrm{~h}$, rising to about $2 \mathrm{fmol} /$ blastocyst after $3 \mathrm{~h}$ incubation. From the information given, it is not possible to calculate the percentage conversion of the radiolabelled substrate. These authors found a slight, but significant, increase in production with time. In the present experiments no such time effect was observed. Approximately $0 \cdot 14 \%$ of the radiolabelled arachidonic acid added to the incubation tube was converted in $1 \mathrm{~h}$ to prostanoids. Kasamo et al. (1986) reported a $1.86 \%$ conversion of $\left[{ }^{14} \mathrm{C}\right]$ arachidonic acid to PGF-2 $\alpha$ by rabbit blastocysts in $1 \mathrm{~h}$, but this calculation was made by dividing the radioactivity for this area on the t.l.c. plate "by the total one recovered after the extraction and t.l.c. of $0.5 \mathrm{ml}$ of the medium containing $0.5 \mu \mathrm{Ci} / \mathrm{ml}$ of" $\left[{ }^{14} \mathrm{C}\right]$ arachidonic acid. Thus, the conversion rate they report is likely to be overstated. In addition, they added $1 \mathrm{~mm}$-adrenaline to the incubation as a co-factor, and this is known to stimulate PG synthesis by microsomal preparations (Blackwell et al., 1975) and change the proportions of the various PGs synthesized (Samuelsson, 1970). In general, in the presence of adrenaline or noradrenaline more PGF-2 $\alpha$ than PGE-2 is produced (Blackwell et al., 1975; Valenzuela \& Harper, 1976), and this could be an explanation for the failure of Kasamo et al. (1986) to detect PGE-2 in their experiments. The solution used in the present study to elute PGs from the h.p.l.c. column, not only does not elute arachidonic acid, but also does not elute leukotrienes. It cannot therefore be assumed that products 
of the lipoxygenase pathway are not formed. Indeed, Pakrasi et al. (1985), using RIA, reported the presence of 5-HETE in Day-6 rabbit blastocysts.

Since others have shown that stimulation of cholinergic-muscarinic receptors causes phospholipid turnover, release of arachidonic acid and increased PG production (Yousufzai \& Abdel-Latif, 1984), and since we had evidence of specific binding of $\left[{ }^{3} \mathrm{H}\right]$ quinuclidinyl benzilate (QNB), a ligand for such receptors (Fields et al., 1978), to rabbit blastocysts (Jones \& Harper, 1985), we investigated the effects of atropine and carbachol in the synthesis experiments. Our expectation had been that in the presence of EDTA, when endogenous phospholipids are stabilized, carbachol might be inhibitory and atropine without effect, or stimulatory if endogenous phospholipid turnover could be further reduced. In the absence of EDTA, we hoped that atropine would be stimulatory, and carbachol inhibitory or without effect. In fact, neither compound had any obvious action in either situation, with perhaps the exception that less of the unidentified metabolite was formed in the presence of carbachol. It therefore seems that this failure is due to the lack of neural control of blastocysts, failure of activation or inhibition of QNB binding sites to influence phospholipid turnover in blastocysts or misinterpretation of the significance of the QNB binding previously observed.

We thank Elizabeth Hemmick for technical assistance; Gretta Small for editorial help; and John D. Schoolfield, Department of Information Technology, UTHSCSA, for performing the statistical analyses. Supported in part by NIH grant HD 14048.

\section{References}

Albert, D.H. \& Snyder, F. (1983) Biosynthesis of 1-alkyl2-acetyl-sn-glycero-3-phosphocholine (Platelet-activating factor) from 1-alkyl-2-acyl-sn-glycero-3-phosphocholine by rat alveolar macrophages. $J$. biol. Chem. 258, 97-102.

Biggers, J.D., Leonov, B.V., Baskar, J.F. \& Fried, J. (1978) Inhibition of hatching of mouse blastocysts in vitro by prostaglandin antagonists. Biol. Reprod. 19 , 519-533.

Biggers, J.D., Baskar, J.F. \& Torchiana, D.F. (1981) Reduction of fertility of mice by intrauterine injection of prostaglandin antagonists. J. Reprod. Fert. 63, 365-372.

Bito, L.Z., Davson, H. \& Salvador, H. (1976) Inhibition of in vitro concentrative prostaglandin accumulation by prostaglandins, prostaglandin analogues and by some inhibitors of organic anion transport. $J$. Physiol., Lond. 256, 257-271.

Blackwell, G.J., Flower, R.J. \& Vane, J.R. (1975) Some characteristics of the prostaglandin synthesizing system in rabbit kidney microsomes. Biochim. Biophys. Acta 398, 178-190.

Davis, D.L., Pakrasi, P.L. \& Dey, S.K. (1983) Prostaglandins in swine blastocysts. Biol. Reprod. 28, 1114 1118.

Dey, S.K., Chien, S.M., Cox, C.L. \& Crist, R.D. (1980) Prostaglandin synthesis in the rabbit blastocyst. Prostaglandins 19, 449-453.

Dickmann, Z. \& Spilman, C.H. (1975) Prostaglandins in rabbit blastocysts. Science, N.Y. 190, 997-998.

Eling, T., Warnock, R., Dick, D. \& Tainer, B. (1980) Separation of prostaglandins, thromboxane, hydroxy fatty acids and arachidonic acid by high pressure liquid chromatography. Prostaglandins 5, 345-355.

Fields, J.Z., Roeske, W.R., Morkin, E. \& Yamamura,
H.I. (1978) Cardiac muscarinic cholinergic receptors. J. biol. Chem. 253, 3251-3258.

Harper, M.J.K., Norris, C.J. \& Rajkumar, K. (1983) Prostaglandin release by zygotes and endometria of pregnant rabbits. Biol. Reprod. 28, 350-362.

Harper, M.J.K., Jones, M.A. \& Norris, C.J. (1987) Synthesis of prostaglandins by day 6 rabbit blastocysts in vitro. Biol. Reprod. 36 (Suppl. 1), p. 59, Abstr. 39.

Homa, S.T., Racowsky, C. \& McGaughey, R.W. (1986) Lipid analysis of immature pig oocytes. J. Reprod. Fert. 77, 425-434.

Hurst, P.R. \& MacFarlane, D.W. (1981) Further effects of nonsteroidal anti-inflammatory compounds on blastocyst hatching in vitro and implantation rates in the mouse. Biol. Reprod. 25, 777-784.

Hwang, D.H., Pool, S.H., Rorie, R.W., Boudreau, M. \& Godke, R.A. (1988) Transitional changes in arachidonic acid metabolism by bovine embryos at different development stages. Prostaglandins 35, 387-402.

Hyland, J.H., Manns, J.G. \& Humphrey, W.D. (1982) Prostaglandin production by ovine embryos and endometrium in vitro. J. Reprod. Fert. 65, 299-304.

Jones, M.A. \& Harper, M.J.K. (1984) Rabbit blastocysts accumulate $\left[{ }^{3} \mathrm{H}\right]$ prostaglandins in vitro. Endocrinology 115, 817-823.

Jones, M.A. \& Harper, M.J.K. (1985) Rabbit blastocysts bind $\left[{ }^{3} \mathrm{H}\right] q u i n u c l i d i n y l$ benzilate (QNB). Proc. 32nd A Mtg Soc. Gynecol. Invest., Phoenix, p. 187, Abstr. $322 \mathrm{P}$.

Jones, M.A. \& Harper, M.J.K. (1988) Effects of Iloprost, a stable prostacyclin analog, $\mathrm{PGE}_{-2}$ and $\mathrm{PGF}_{-2 \alpha}$ on rabbit blastocysts. Gamete Res. 20, 203-213.

Jones, M.A., Anderson, W., Turner, T.G. \& Harper, M.J.K. (1985) Storage in vivo of $\left[{ }^{3} \mathrm{H}\right]$ prostaglandins by ra obit blastocysts. Endocrinology 116, 993-997. 
Jones, M.A., Cao, Z.-d., Anderson, W., Norris, C. \& Harper, M.J.K. (1986) Capillary permeability changes in the uteri of recipient rabbits after transfer of blastocysts from indomethacin-treated donors. $J$. Reprod. Fert. 78, 261-273.

Kasamo, M. (1985) Experimental studies on the mechanism of implantation observed from PGF levels. Acta obstet. gynaec. jap. 37, 83-91.

Kasamo, M., Ishikawa, M., Yamashita, K., Sengoku, K. \& Shimizu, T. (1986) Possible role of prostaglandin F in blastocyst implantation. Prostaglandins 31, 321336.

Lewis, G.S., Thatcher, W.W., Bazer, F.W. \& Curl, J.S. (1982) Metabolism of arachidonic acid in vitro by bovine blastocysts and endometrium. Biol. Reprod. 27, 431-439.

Marcus, G.J. (1981) Prostaglandin formation by the sheep embryo and endometrium as an indication of maternal recognition of pregnancy. Biol. Reprod. 25, 56-64.

Melendez, E. \& Reyes, J.L. (1982) Renal handling of indomethacin and its relationship with the secretory pathways of prostaglandins. J. Pharm. Pharmacol. 34, 648-652.

Mukherjee, A., Dey, S.K., Gupta, J.S., Ramadoss, C.S. \& Dickmann, Z. (1978) Regulatory enzymes of carbohydrate and energy metabolism in the rabbit blastocyst. J. Reprod. Fert. 53, 77-80.

Pakrasi, P.L. \& Dey, S.K. (1982) Blastocyst is the source of prostaglandins in the implantation site in the rabbit. Prostaglandins 24, 73-77.
Pakrasi, P.L., Becka, R. \& Dey, S.K. (1985) Cyclooxygenase and lipoxygenase pathways in the preimplantation rabbit uterus and blastocyst. Prostaglandins 29, 481-495.

Racowsky, C. \& Biggers, J.D. (1983) Are blastocyst prostaglandins produced endogenously? Biol. Reprod. 29, 379-388.

Samples, D.R., Harper, M.J.K. \& Herlihy, J.T. (1988) Arachidonic acid losses due to adsorption to glass tissue baths. Faseb J. 2, A1571, Abstr. 7408.

Samuelsson, B. (1970) Lipid Metabolism, pp. 107-153. Academic Press, New York.

Sharma, S.C. (1980) Temporal changes in PGE, PGFa, oestradiol-17 $\beta$ and progesterone in uterine venous plasma and endometrium of rabbits during early pregnancy. In Les Colloques de l'Inserm Prostaglandines et Physiologie de la Reproduction, pp. 243-263. Eds A. Crastes de Paulet, H. Thaler-Dao \& F. Dray. Inserm, Paris.

Shemesh, M., Milaguir, F., Ayalon, N. \& Hansel, W. (1979) Steroidogenesis and prostaglandin synthesis by cultured bovine blastocysts. J. Reprod. Fert. 56, 181-185.

Valenzuela, G. \& Harper, M.J.K. (1976) Effect of estrogen on activity of prostaglandin synthetase in rabbit oviduct. Prostaglandins 12, 535-549.

Yousufzai, S.Y.K. \& Abdel-Latif, A.A. (1984) The effects of alpha-adrenergic and muscarinic cholinergic stimulation on prostaglandin release by rabbit iris. Prostaglandins 28, 399-415.

Received 19 September 1988 